\title{
The Innovation Research of Informatization Service System on Farmer Specialized Cooperative
}

\author{
Qianru $\mathrm{Li}^{1, \mathrm{a}}$ and Haiying $\mathrm{Ma}^{2, \mathrm{~b}}$ * \\ ${ }^{1,2}$ School of Economics, Northwest University for Nationalities, Lanzhou (730124), P.R. China \\ a942798353@qq.com, blxmahaiying8888@163.com
}

\begin{abstract}
Keywords: Farmer specialized cooperative; Information technology; Informatization service system;
\end{abstract} Information service

\begin{abstract}
With the steadily advancing of agricultural modernization, realizing the sustainable development of farmer specialized cooperative had the great practical significance to solve the "three rural" issues. This paper made a substantial investigation on the current situation of farmer specialized cooperatives in Wenzhou, and analyzed the main problems that restrict the development of the informatization service of the farmer specialized cooperatives. Based on the perspective of information technology, this paper put forward a new information service system which was suitable for the development of farmer specialized cooperatives from three aspects: The internal organization, the external organization and the organizations.
\end{abstract}

\section{Introduction}

As a new type of farmers economic development in China, farmers' professional cooperatives is not only to provide a platform for small farmers and large market docking, but also provide agricultural information, production technology, product sales, market information and other services for small farmers. It effectively promote the farmers income, agricultural efficiency, rural development and to provide information support to solve the three rural issues. Since 2007, farmer cooperatives has been developed vigorously, as of the end of December 2014, the total number of farmers cooperatives in China reached 1 million, an increase of $31.18 \%$ over the previous year. Farmer cooperatives play an important role in promoting the rural management system to adapt to the development of modern agriculture. With the construction of informatization of our country agriculture development, it is an important issue to realize the healthy and orderly development of the farmers professional cooperatives to explore the advantages of farmers' professional cooperatives with information technology and explore a path of development of information service for farmers professional cooperatives in China.

It is of great reference value to review the research literature of farmers' professional cooperatives in China. Because some foreign countries have developed several decades of professional cooperatives, especially agricultural science and technology services started early, And it developed fast, also the effect was good. As the application of decision support system in agricultural field can help decision makers to make better decisions and improve the accuracy and competitiveness. The application of information technology in the beef industry is conducive to promoting the healthy development of the main links of the supply chain, but also conducive to the development of the main body of various links, such as enterprises and cooperatives. Chieochan and other people analyzed the impact factors of the use of information technology in Thailand farmer cooperatives, mainly divided into internal factors and external factors. Among them, the internal factors are divided into two aspects: the characteristics and organization characteristics of cooperative management; external factors are political, economic, social and infrastructure, to greatly improve the farmer specialized cooperatives in Thailand by using information technology. Rupak Chakravarty argued that Information technology has affected the milk production of dairy farmers in India, $\mathrm{He}$ cited an example of India national dairy development board development of the dairy industry is the key by application of information technology, so greatly improve the speed and quality of the milk collection 
efficiency and quick service to farmers, so as to solve the traditional problems in operation, the India dairy industry has undergone tremendous changes.

Domestic scholars study the main information platform system, information systems, information technology and related services and so on. As Wang in applying information technology to the cooperative organizations, on the basis of all aspects of the management, on the development of Xiang Yin Xiang farmers professional cooperative research on the comprehensive information platform; Liu zhongqiang from supply logistics management system construction, and tracing management system construction, and technology service information system construction, and decision support system construction and portal website construction, aspects. Sun Xiang based on information resources aggregate and farmers professional cooperatives information as well as information releasing difficult with cost high, he proposed on farmers professional cooperatives information aggregate Yuan data collected specification building a two-tier deployment system of farmers professional cooperative information systems. Bai put forward a series of policy suggestions to strengthen the information construction of farmers' professional cooperatives. Cai expounds the feasibility of informatization construction of the potential advantages and opportunities to build farmer cooperatives and farmer cooperatives website production, processing, sales information integration service system. The angle of information technology in Wenzhou city based on the farmers' professional cooperatives as an example, the empirical research and analysis of the informatization construction, from the cooperative organization, outside the organization, to build a new information service system for the development of farmer professional cooperatives in the three aspects of organization, useful exploration and Research on it.

\section{Investigation and Analysis on Cooperatives Information Status}

Based on the factors of farmer cooperatives development basic situation and its impact on the construction of information service demand and information construction, provide the basis for our next step of scientific planning of farmer cooperatives information service development, we selected some typical Wenzhou area farmer cooperatives questionnaire survey as samples, a total of 87 questionnaires, 54 valid questionnaires and the effective rate was $62.07 \%$. According to the statistics, in the study of farmer cooperatives industry mainly related to farming, fisheries, forestry, service industry and other industries accounted for 37.04\%, 24.07\%, 16.67\%, 11.11\%, 9.26\% and 1.85\%.

Investigation and Analysis on Informatization Construction of Hardware and Software. From the cooperative information hardware infrastructure research, the surveyed cooperatives equipped with computer terminal equipment accounted for $96.3 \%$ of all equipment, which cooperatives with more than 2 computers, but in the following five computers and equipped with a computer more common, respectively Accounting for $38.90 \%$ and $33.33 \%$; with more than 6 computers and equipped with more than 10 computer cooperatives accounted for $20.37 \%$ and $3.7 \%$. Survey data from cooperatives information software talent, there are $42.59 \%$ who has a full-time information officer working in the information, the number is greater than one but less than three of the more common; there is no full-time information member cooperatives, $57.41 \%$ set up a part-time information officer. In addition, surveyed the cultural quality of information is a primary school, middle school, high school, College, undergraduate degree or above accounted for $3.70 \%, 26.52 \%$, $37.4 \%, 30.89 \%$ and $1.85 \%$.

Investigation and Analysis of Information System Applications. From the application of information systems of cooperative research with information service consciousness, but only $46.30 \%$ of the cooperative construction of basic database for data management and information service. In "whether there is internal in the cooperative use of information technology, data organization and organization between the external application of information system for daily management and service" that is the application of internal financial management system, file management system as the main members of cooperatives daily financial expenditure management and membership management of basic information, accounted for $90.74 \%$ and $51.85 \%$, part of the 
cooperative use of members of the internal office automation system in the internal management, to facilitate the standardized management and thorough service to members. The main external organization is to do foreign product promotion, sales, The circulation management work, the use of farmer cooperatives website, network marketing system, product circulation management system accounted for $82.48 \%, 55.56 \%$ and $20.37 \%$ by information technology hardware and software, limited funds and other financial conditions, product quality and safety traceability management system and service system in the practical application of the proportion of members. With the construction of information development and management standardization the development of the system, relying on the product quality and safety and improve the two-way traceability management services to the members will become the future trend of development.

Investigation and Analysis of Influencing Factors of Informatization Construction. From the influence factors of informatization construction of cooperative research, through the analysis and statistics of questionnaire data in Table 1, the summary statistics show that the factors affecting the development of cooperatives information includes: government, cooperatives, members. The government support of cooperatives information construction is not enough for the main factors accounted for $88.89 \%$, the lack of high-quality talent cooperative information officer and cooperative on informatization construction funds shortage accounted for $72.22 \%$ and $61.11 \%$, the cooperative ability of computer application and the role of members in addition information understanding insufficiency accounted for $46.30 \%$ and $31.48 \%$., through field investigation found that $42.59 \%$ of the cooperatives developed a plan for the construction and development of information systems, $46.30 \%$ through cooperatives Provide relevant computer skills training to improve the membership level of computer operation.

Table 1 Influence factors of farmer cooperatives informatization construction in Wenzhou City

\begin{tabular}{lcc}
\hline \multicolumn{1}{c}{ Description } & $\begin{array}{c}\text { The number of } \\
\text { cooperatives(ea) }\end{array}$ & $\begin{array}{c}\text { The percentage of } \\
\text { cooperatives(\%) }\end{array}$ \\
\hline Lacking of government information technology support & 48 & 88.89 \\
Cooperatives lack information talents with high quality & 39 & 72.22 \\
lacking of capital investment & 33 & 61.11 \\
Lacking of systematic information technology planning & 31 & 57.41 \\
Lacking of computer skills & 25 & 46.30 \\
Lacking of knowledge of the role of information & 17 & 31.48 \\
technology & & \\
\hline
\end{tabular}

\section{Problems in Farmers Professional Cooperative Information Services}

Poor Infrastructure and lack of Information Personnel. Information infrastructure is the guarantee of cooperatives to achieve information service of hardware. According to the research situation, the cooperative is equipped with computer terminal equipment units, equipment is relatively backward, the construction of cooperative information infrastructure is not balanced, so it is necessary to increase capital investment, improve the existing infrastructure. In addition, both agricultural knowledge and information knowledge of composite information talent is to promote cooperatives to achieve information service software at present conditions. Information and cultural level is not high in cooperative information, lack of analysis and processing ability and awareness of information resources, do not pay attention to the training of information education, the lack of qualified personnel. Therefore, cooperative information construction must pay attention to the infrastructure and the construction of talent team the integration of hardware and software, to play its advantages. 
The Backward of Service Consciousness. With the development of information technology and the Internet, the information service and cooperative network operation consciousness strengthens gradually, but the application in cooperative organization, organization, information service means lag between organizations, most of the information system is simple to be applied to the cooperative foundation of comprehensive information management, such as financial management, members of Archives management no, portals, most involving the application of information mining and information decision-making; a considerable proportion of the cooperatives in various information systems do not have a deep understanding, such as product quality and safety traceability management system, geographic information system, expert online answering system, but not involved in the business process by using all kinds of information system integration of information resources. Therefore, cooperatives need to strengthen awareness of information services to improve their information literacy with various information systems and information technology.

Insufficient Capital Investment and Policy Support. Capital investment is a key factor affecting the success of cooperatives information construction. According to the survey, most cooperatives informatization construction funds for the self financing mode. Although part of the cooperative with information construction and development planning system, but by the capital bottleneck, provide basic computer skills training only to members, unable to provide more and the sustainability of the training. In the aspect of promoting the rapid development of information construction in rural areas, the government should actively play its leading role in coordinating relevant departments of agriculture, increase the input of public finance, rural information construction ground, especially in the cooperative funds and increase efforts to support computer training, and constantly improve the cooperative information service system.

\section{Conclusions}

Cooperative Organization Information Service Platform. The construction of information service platform for cooperative organization is the main means of information as a tool, the spirit of convenient, practical and efficient principle, one of the cooperative internal management processes effectively reorganization and integration, improve work efficiency. the second is on the different levels of cooperatives members of the role including organization management, financial personnel, inventory personnel, farmer members of a unified and convenient management. According to the different needs of cooperative organization, many information system products have emerged, such as members of the internal office automation system, financial management system, the training system of members, members of the file management system, agricultural information resources management system. The concept of enterprise based on ERP, members of the internal office automation system is to solve the cooperative production, warehouse, sales and other daily process management, information collection and information processing in all aspects, The cooperatives in various positions of the members can work together quickly and efficiently, achieve the expected purpose of office automation, standardization and scientific. Financial management system is mainly to solve the cooperative daily account management, including statistics, monthly settlement, inventory accounting, earnings return business process, realize the dynamic control of capital flow and the use of enhanced cooperative funds transparency.

Cooperative Organization External Information Service Platform. The construction of external information service platform is mainly cooperative use of information technology to the Internet as a medium build between cooperatives and outside market docking comprehensive information network platform, such as network marketing system, product circulation management system, product quality and safety traceability management system, membership service system, farmers cooperatives website. The system is mainly for network marketing products to solve the difficult problem of Cooperative Sales of agricultural products, the concept of electronic commerce to change the traditional sales model based on, through the establishment of product promotion, information dissemination and collection, customer service, network transactions and other 
functional modules, to achieve break the constraints of time and space, expand the sales network channels. Product distribution management system is based on the industrial chain of agricultural products based on supply chain management as the key point, can effectively solve the various problems caused by the circulation of agricultural products in the middle of asymmetric information, and with the use of network marketing system can realize the management of production and marketing integration, will increase the income of cooperatives to a great extent.

The Cooperative Organization between the Information Service Platform. The construction of information service platform between cooperative organizations, mainly by the state, local government, cooperatives and other multi social forces to informatization construction as the starting point, actively to the farmers' professional cooperatives to create groups and guide information system products, for different industries, the actual characteristics of scale and level of cooperative development, designed to meet the different the cooperative organization requirements of information system software, such as cooperatives unified management portal, geographic information system (GIS), regional cooperative information database system, agricultural product market information analysis system, expert online answering system, establish and improve the modern agricultural information system, promote the development of cooperative information service.

\section{References}

[1] Cox P G, Some Issues in the Design of Agricultural Decision Support Systems, Agricultural Systems. 2(1996)355-381.

[2] Victoria Salin, Information Technology and Cattle-beef Supply Chains, American Journal of Agricultural Economics. 2(2000) 1105-1111.

[3] Chieochan O, Lindley D Dunn T, Factors Affecting the Use of Information Technology in Thai Agricultural Cooperatives: A Work in Progress, The Electronic Journal of Information Systems in Developing Countries. 21(2000) 1-15.

[5] Wang Zhijun, Miao Liang, Liang Yong, Study on Information of Farmers ' Professional Cooperatives[J]. Agricultural Network Information. 7 (2008) 39-41.

[6] Liu Zhongqiang, Wang Kaiyi, Yu Gang and so on. Research on farmers professional cooperative information technology plan, Study on Agricultural Mechanization. 4 (2014) 1-4.

[7] Bai Ling, Ma Yan, Discussion on the informatization construction of farmers professional cooperatives in Anhui Province- some thoughts on the informatization construction of cooperative, China's Information Industry. 8 (2012) 14-18.

[8] Cai Peiliang, Study on the informatization construction of farmers professional cooperatives in underdeveloped regions in Fujian province, Journal of Agronomy. 8 (2013) 69-74.

[9] Sun Xiang, Li Qingxue, Information resource aggregation based on farmers professional cooperative information systems, Computer Engineering and Design. 4(2010)3697-3701.

[10] Huang Jianxin, Based on the farmers professional cooperative science and technology service system construction research, Forum in Fujian province (Humanities and Social Science Edition). 10 (2014)148-151.

[11] Li Xiaoying, Wu Lang, Farmers professional cooperative information and technology service system approach research of the realization, Agricultural Network Information. 7 (2014)38-41. 